\title{
Lung re-inflation after one-lung ventilation for thoracic surgery: importance of clamping the dependent lung
}

\author{
Gerard Bruin, MD
}

Received: 10 June 2014/ Accepted: 7 August 2014/Published online: 21 August 2014

(C) Canadian Anesthesiologists' Society 2014

\section{To the Editor,}

Our thoracic surgeons routinely request that continuous positive airway pressure (CPAP) be applied to the nondependent (i.e., operated on) lung either to test the bronchial staple line after resection or to ensure lung reexpansion prior to chest closure. Although we generally use low airway pressure (i.e., $<15 \mathrm{~cm} \mathrm{H}_{2} \mathrm{O}$ ), at times up to $30 \mathrm{~cm} \mathrm{H}_{2} \mathrm{O}$ is needed to expand portions of the lung that have been chronically atelectatic. Application of these pressures to both lungs may result in the relatively compliant dependent lung receiving a greater proportion of the gas flow, which can increase its risk of volutrauma. In addition, prolonged inflation with relatively high pressures can excessively increase intrathoracic pressure and even result in a mediastinal shift, each of which can reduce venous return and lead to hypotension.

In order to reduce these consequences, prior to applying the CPAP, we suspend ventilation and clamp the dependent lung lumen of the double-lumen endotracheal tube, thereby stopping gas flow to that lung. This measure not only protects the dependent lung from the high airway pressures, but also reduces the duration of CPAP application by expanding the non-dependent lung more rapidly, and thus decreases the risk of prolonged reduction in venous return.

Although clamping the dependent lung prior to applying CPAP to the operative lung is not a novel technique, ${ }^{1}$ it has come to our attention that many anesthesiologists have not considered it. Indeed, residents who have come to our hospital for exposure to community anesthesia practice frequently note that this technique has not been taught in their training programs. Also, after observing the technique, they have expressed appreciation of its advantages.

A potential objection to clamping flow to the dependent lung during a CPAP test is the potential to subjecting the patient to the risk of hypoxemia or hypercapnea. We have not found this been an issue, however. If anything, oxygen saturation improves as the alveoli are opened. Also, suspending ventilation for less than the minute it usually takes to re-expand the lung is unlikely to increase $\mathrm{CO}_{2}$ to any significant degree. Importantly, we have not observed hypotension during re-inflation using this lung-clamping CPAP technique.

Despite the fact that there have been no clinical studies to determine that any one technique for lung re-expansion provides better results than any other, we think that this technique is a logical and relatively safe method to prevent potential volutrauma and/or hypotension.

Conflicts of interest None declared.

\section{Reference}

1. Butterworth JF, Mackey DC, Wasnick JD. Anesthesia for thoracic surgery. In: Butterworth JF, Mackey DC, Wasnick JD, editors. Morgan \& Mikhail's Clinical Anesthesiology. 5th ed. NY: McGraw-Hill; 2013. p. 545.
G. Bruin, MD ( $\square)$

Trillium Health Partners, Credit Valley Hospital, Mississauga, ON, Canada 